\title{
Single-stage treatment of chronic localized tibial osteomyelitis with local debridement and antibiotic-loaded calcium sulfate implantation:a retrospective study of $\mathbf{4 2}$ patients.
}

\section{Chun-Hao Zhou}

Southern Medical University Nanfang Hospital

Ying Ren

Southern Medical University Nanfang Hospital

\section{Abdulnassir Adem}

Southern Medical University Nanfang Hospital

Xiang-Qing Meng

Guangdong Second Provincial General Hospital

Hong-An Zhang

Guangdong Second Provincial General Hospital

Jia Fang

Guangdong Second Provincial General Hospital

Cheng-He Qin ( $D$ orthoqin@163.com )

Guangdong Second Provincial General Hospital https://orcid.org/0000-0002-5472-7964

\section{Research article}

Keywords: chronic localized tibial osteomyelitis, local debridement, antibiotic-loaded calcium sulfate implantation

Posted Date: March 2nd, 2020

DOl: https://doi.org/10.21203/rs.2.19919/v2

License: (c) (i) This work is licensed under a Creative Commons Attribution 4.0 International License. Read Full License

Version of Record: A version of this preprint was published at Journal of Orthopaedic Surgery and Research on June 1st, 2020. See the published version at https://doi.org/10.1186/s13018-020-01721-7. 


\section{Abstract}

Background: The management of chronic tibial osteomyelitis is still a challenge, even with various methods have been introduced. This study aims to assess a combined treatment method, local debridement combined with antibiotic-loaded calcium sulfate implantation, for the management of the local (Cierny-Mader type III) tibial osteomyelitis.

Methods: 42 patients (43 limbs) with type III tibial osteomyelitis, from January 2012 to December 2018, who received above mentioned treatment method were included in the study. The infection remission rate, recurrence rate, complication rate and bone healing rate were respectively analyzed.

Results: With a mean follow-up of 42.8 months, 38 limbs (37 patients) $(88.4 \%, 38 / 43)$ achieved infection remission without recurrence. Among those patients, pain, limitation of movement, sinus tracts, topical redness and swelling were generally eliminated. Only 4 patients felt slight pain after a long-distance walk, while another 6 patients showed slight but acceptable discomfort in affected limbs. 5 patients (11.6\%) suffered from osteomyelitis recurrence that required secondary surgical and medical treatment, but no amputation was necessary to eliminate the infection. Prolonged aseptic drainage was the most frequent complication that was observed in 13 patients (30.0\%). They were successfully managed by appropriate wound caring in 10 patients and by surgical intervention, months later, in 3 patients. According to the final X-rays examination, bone losses caused by local debridement were generally repaired, though the shape of tibia was not well restored to its initial form in 17 limbs. No fracture was recorded during follow-up.

Conclusion: Local debridement combined with antibiotic-loaded calcium sulfate implantation is effective and safe in a single-stage treatment of chronic Cierny-Mader III tibial osteomyelitis.

\section{Background}

Chronic tibial osteomyelitis is defined as long-term infection of tibia and characterized by low-grade inflammation with sequestrum or fistulous tract[1]. Secondary to the increased trauma, inappropriate application of implants or prolonged haematogenous infection, it has become a less rare disease the orthopedists have to face. Once established chronic tibial osteomelitis, the risk of leading to a variety of disastrous complications, such as pathological fracture, delayed healing or nonunion or even major amputation, significantly reducing the quality of life. Therefore, immediate and appropriate management is vital for patients with chronic tibial osteomyelitis. Unfortunately, even standard treatment protocols have been strictly carried out, chronic tibial osteomyelitis remains a refractory disease with noticeable recurrent rate of $20 \%$ to $30 \%$ [2].

In order to help planning the surgical strategy and improving the effects of treatment,a physiology and anatomy-based osteomyelitis classification system was introduced by Cierny and Mader in 1985[3], which now has been widely accepted as the standard classification for chronic long bone osteomyelitis. According to anatomic osseous involvement[4][4], Cierny et al firstly divided chronic osteomyelitis into four types: medullary (type I), superficial (type II), localised (type III) and diffused (type IV), and further classified patients into three groups: healthy patients (group A), compromised patients (group B) and patients who were too weak to receive surgery (group C), based on the physiologic status of patients. Attributing to the limited involvement, localized tibial (C-M type III) osteomyelitis is not as complicated as the diffused one (type IV), but still owning its characteristics. Since the extent of infection is comparatively limited, the clinical symptoms and presentations might not be as severe as the diffused osteomyelitis, which means a better outcomes could be achieved if treated immediately and appropriately. In the aspect of surgical management, local debridement without segmental bone resection as the standard surgical management allows the restoration of enough healthy bones, which avoids the massive bone loss and tedious secondary reconstruction to restore the length of tibia[5, 6].

With regard to the dead space, second-staged muscle flaps or autogenous cancellous bone grafts after weeks of systemic antibiotics administration, are traditional but effective treatment methods[6, 7]. However, their drawbacks lies in the necessity of multiple staged and complicated surgical management, long-term systemic antibiotics application, sometimes even 
accompanied with severe donor sites complications, all of which inevitably increases burdens on both doctors and patients. To overcome those drawbacks, topical antibiotics carrier is a promising method. Since Buchholz successfully applied it in joint prosthesis, polymethyl-methacrylate cement (PMMA) has acted as an antibiotic carrier to fill the defects caused by debridement [8]. It limited the long-term systemic antibiotics application and eliminates more residual bacteria by its higher local antibiotic concentrations. However, its drawback was that it required second procedure for removal and autogenous tissue grafts. Moreover, the high temperature it produces limits the application of temperature sensitive antibiotics to some extent. Its surface also provide a place for pathogens implantation if not removed in a timely manner, increasing the possibility of infection recurrence or a new infection. Therefore, a substitute biodegradable material is imperative. Highly purified calcium sulfate as the most common biodegradable antibiotic-impregnated materials is widely used on the treatment of osteomyelitis in latest decades, and the overall results were good[9, 10]. After implantation, it is associated with the advantages of more accurate positioning, higher local concentration, less side effects, longer treatment duration as well as its potential osteoconductivity[11,12], while overcoming the shortcomings of non-biodegradable antibiotic carriers.

Statistically, tibia is the most common sites for chronic osteomyelitis taking place[7, 13], partially because of its poor blood supply (especially inferior third of tibia), only skin coverage in medial surface, higher risk of injuries and of course, the inappropriate surgical managements. C-M Type III chronic tibial osteomyelitis as the less severe type has not yet received much attentions as C-M type IV, thus is not frequently illustrated by a single study. Separate studies on localized tibial osteomyelitis alone are still not substantiated. Our study is designed to assess the outcomes of local debridement combined with a substitute of autologous bone, the antibiotic-loaded calcium sulphate, for single-stage treatment of localized chronic tibial osteomyelitis.

\section{Patients And Methods}

\section{Patients and preoperative management}

From January 2012 to December 2018, hundreds of patients with chronic tibia osteomyelitis were treated in our center, but only those meeting the following criteria were included in this study. 1) Diagnosed with C-M type III chronic tibial osteomyelitis and treated in our department. 2) Completed follow-up of a minimum of 12 months. 3) The surgery performed was fenestration and debridement combined with placement of antibiotic-loaded calcium sulphate. On the contrary, patients with host-C class or received other treatment methods were excluded form the study.

Totally, 42 patients with 43 limbs [ 24 men and 18 women (19 limbs); average age: 43.7 years (range, 23-74 years)] met the criteria were included for analysis. There were 24 (55.8\%) infection focal on the left tibia, and 19 (44.2\%) on the right tibia. At least 2 patients were recorded as a smoker and the other 2 patients were diagnosed with hypertension. Regarding physiologic status of patients, 35 patients (36 limbs) were defined as C-M type IIIA compared to 7 patients as C-M type IIIB (6 cases with type $I I \mathrm{~B}^{S}$ and 1 with type $I I I B^{L}$ ). While majority of patients were accompanied with pain, draining sinus, swelling and slight movement limitation, 14 patients were presented with pain or swelling only. The osteomyelitis of those cases were primitively suspected by recurrent pain or arisen temperature on topical sites, and eventually diagnosed by active MRI results and arisen inflammation markers. According to etiology, trauma was the number one cause for infection with (31 limbs), which was further divided into open tibial fracture (12 limbs) and closed fracture with ORIF (19 limbs). Hematogenous infection as the second common causes of infection was generally recorded in 10 limbs. Followed by penetration from soft tissues infection in third place (2 limbs). The details of all patients were presented in table 1.

Once admitting to the department, all patients were suggested to receive physical examinations, X-rays, and laboratory tests. Preoperative Magnetic resonance imaging (MRI) examination was accomplished in the following days for determining the extent of infection. To avoid the interference of biopsy culture, empirical antibiotic administration was not started until samples had been obtained for culture during surgery. Preoperative laboratory results showed, mean erythrocyte sedimentation rate (ESR) $23.22 \mathrm{~mm} / \mathrm{h}$, mean C-reactive protein (CRP) level $3.41 \mathrm{mg} / \mathrm{L}$, and mean white blood cell (WBC) 
$6.71 \times 10^{9} / \mathrm{L}$. Intra-operative topical antibiotics of those cases included both vancomycin and gentamicin, in order to cover both Gram-positive and negative bacteria.

Figure 1. Preoperative MRI examination significantly assisted to define the diagnosis of C-M type III osteomyelitis and determine the extent of debridement.

Table 1. Preoperative characteristics and follow-up outcomes of 42 patients (43 limbs).

\section{Surgical technique}

Surgical procedures were carried out by experienced surgeons after spinal or nerve block anesthesia. Removal of sinus or ulcer was performed first, followed by extensive debridement of necrotic soft tissues and fibrotic scar tissues surrounding the bone area, in order to sufficiently expose the infected cortex. Any adjacent internal fixations on tibia must be removed before debriding. Local fenestration was then carried out with the help of the high-speed burr and osteotome. The size of cortical bone fenestration was dependent on the extent of infection bone area, which was determined by the pre-operative MRI examination and intra-operative presentations, such as the "Paprika sign". Conventionally, debridement was suggested to contain the whole infected area as well as at least $5 \mathrm{~mm}$ healthy bone tissues[14], for exposing the focus adequately and preventing the infection recurrence as possible. Following fenestration, intramedullary debridement was started by removal of pus, inflammatory granulation and sequestrums with a rongeur. The samples were collected for bacterial culture and histological examination. After initial debridement, intramedullary reaming, irrigation and aspiration were employed to remove the residual necrotic tissues. Eventually, a trough-like dead space on tibia was created.

Antibiotic-loaded calcium sulfate was prepared with a recommended ratio: $0.5 \mathrm{~g}$ vancomycin powder and $2 \mathrm{ml}$ gentamicin were blended into $5 \mathrm{ml}$ calcium sulphate (Stimulan, Biocomposite Ltd., UK), which then dissolved in $0.5 \mathrm{ml}$ sterile saline and embedded into the bony cavity after sufficient agitation. Attributing to the limited infection of type C-M III osteomyelitis, soft tissues were enough for coverage in 41 wounds, thus those wounds were sutured directly. The other 2 wounds needed flaps coverage (including 1 random flap and 1 anterolateral thigh flap) to eliminate the large soft tissue losses. External fixation was applied in 13 cases with large bony defect, according to surgeon's experience.

Figure 2. Intra-operative views of local debridement and antibiotic-loaded calcium sulfate implantation.

\section{Postoperative management}

After operation, broad-sprectrum antibiotics were applied empirically in the first several days, and exchanged to sensitive antibiotics according to results of culture for no more than 2 weeks. Conventional prolonged systemic antibiotics ( 2 weeks for parental route and another 4 weeks for oral, usually) was not recommended in our study, since the high topical concentration reached by degrading of antibiotic-loaded calcium sulfate. Wound dressings were changed every 2 days, unless excessive drainage was noted in the interval. As most of the cortical bone was preserved, full weight-bearing was encouraged once pain of incision was eased. External fixation was removed if bone union was observed on regular X-ray examination.

Figure 3. A patient with C-M type III tibial osteomyelitis received internal fixation removal and infected bone debridement, followed by implantation of antibiotic-loaded calcium sulfate. X-ray examination during the follow up showed dead space was generally substituted by new bone tissues.

\section{Outcomes evaluation}

Normally postoperative assessment included subjective reports of patients and the objective results such as, clinical examination, X-ray and inflammatory markers. The main outcomes we focused on were infection remission, bone union, infection recurrence and post-operative complications during the follow-up. We defined infection remission as the absence of any signs of osteomyelitis and a completely healed wound. Bone union proved by elimination of bony cavity with the 
formation of new bone tissues. Osteomyelitis recurrence was defined by the presence of clinical symptoms, positive radiographic findings and elevated inflammatory markers. In this study, we defined wound drainage without topical infection symptoms for more than 1 month as prolonged aseptic drainage.

\section{Results}

During a mean follow-up of 42.8 months (12.8 to 77.5 months), we found $88.4 \%$ (38/43) limbs achieved complete infection remission without any recurrence. Only $11.6 \%$ (5/43) limbs suffered from infection recurrence within first three years after operation. The management of those 5 cases were segmental bone resection and bone transport on 4 limbs and redebridement plus flap coverage on $1 \mathrm{limb}$. Postoperative complications of those cases mainly included prolonged aseptic drainage $(30 \%, 13 / 43)$, slight pain after long-distance walk $(10.5 \%, 4 / 38)$, limb weakness or discomfort $(7.9 \%, 4 / 38)$, fibrous scar formation $(5.2 \%, 2 / 38)$, joint stiffness $(2.6 \%, 1 / 38)$ and slight claudication $(2.6 \%, 1 / 38)$. No case was detected with postoperative fracture or tibial bowing during the follow-up. For patients with prolonged aseptic drainage, the most acceptable and effective management was by frequently changing wound dressing, which was successfully applied to 10 limbs. The rest 3 wounds (limbs) were stubborn to the regular dressings. Therefore, surgical assistance was adopted to manage with prolonged aseptic drainage, after the infection had been well controlled. External fixation was adopted in 13 limbs with large bone loss, aiming to maintain the stability and avoid postoperative fracture. During an average fixation time of 11.8 months (3 to 29 months), no fracture or tibial bowing effect was recorded. According to the latest X-ray examination, a generally satisfying bone formation was achieved in all healed limbs, although the shape of tibia was not restored to the initial in 17 cases.

In total, 22 bacterial spices were isolated from 43 samples, with a positive rate of $51.2 \%$. Staphylococcus aureus (50.0\%, $11 / 22$ ) is the most common pathogen isolated by culture, followed by Pseudomonas aeruginosa (13.6\%, 3/22). One case was polymicrobial infections and the bacteria species of which were Enterococcus faecalis and Pseudomonas aeruginosa, respectively. The details of patients were presented in table1.

Figure 4. A patient received local debridement and calcium sulfate implantation. The X-ray after 6 months showed that the shape of tibia shaft was not well restored to the initial, but no fracture was detected.

\section{Discussion}

C-M Type III chronic tibial osteomyelitis as a localized infection involves full-thickness cortical bone as well as the medullary tissue, which may develop to a diffused infection if not well managed. However, impaired local vessels condition on bone sclerosis and sequestrum make it difficult for parental antimicrobial therapy alone to achieve satisfying local effects, even with a prolonged course of application. Besides, Staphylococcus aureus as the most frequent detected pathogen of osteomyelitis prone to produce a biofilm, which irreversibly binds to the surface of the bone and the internal implant, causing the infection stubborn and hard to be eliminated [15]. To address this embarrassing situation, surgical intervention is the cornerstone for the treatment of osteomyelitis, since it not only removes the necrotic tissues but destroys the biofilms caused by pathogens, therefore stimulating the local blood supply and enhancing the antimicrobial effects of antibiotics.

For localized tibial osteomyelitis, surgical principles may be interpreted as the combination of "radicalization" and "limitation". The principle of "radicalization" requires thorough removal of necrotic tissues and some adjacent healthy bone, to create a relatively clean wound for following reconstructive steps, while the principle of "limitation" requires to preserve as much healthy bone as possible (under the premise of thorough debridement, of course), to prevent complication of postoperative fractures or deformities. Therefore, conventional aggressive debridement technique for diffused tibial osteomyelitis, segmental bone resection, is unsuitable for the treatment of localized tibial osteomyelitis. To match the demands mentioned above, local debridement (deroofing associated with the intramedullary debridement) is introduced as the treatment of localized tibial osteomyelitis, and the effects is satisfying. In a former study, Rodney K. Beals et a/ reported 30 consecutive cases with tibial osteomyelitis, which included 1 case with Cierny-Mader type IIIA and the other 8 cases with 
type IIIB. The treatment methods of localized osteomyelitis included local debridement only in 5 cases, local debridement and muscle flaps coverage in 2 cases, and multiple debridement and posterior lateral bone graft in 1 case. All cases achieved good outcomes at the end of follow-up[16]. Hakan Kinik et al treated 26 cases with chronic localized osteomyelitis in his work. Those patients were treated with deroofing and local debridement, irrigation, vancomycin-impregnated PMMA beads implantation at first stage, followed by re-debridement and PMMA beads removal 6 to 8 weeks later. Within a mean follow-up of 3.6 years, all patients received infection remission with normal clinical parameters, even though 3 patients suffered from re-debridement in the interval[6].

In our study, this classical local debridement technique was also introduced for the removal of necrotic tissues. The main difference lies in the replacement of temporary antibiotic-impregnated PMMA beads or autologous tissues grafts with biodegradable antibiotic-impregnated calcium sulfate, which undoubtedly owns its unique advantages. Primarily, the predictable high local antibiotic concentration (hundreds to thousands times higher than MIC in first 24h to $48 \mathrm{~h}$ ) and comparatively long therapeutic duration (several weeks to months) $[5,17,18]$ produced by the degrading antibiotic-loaded calcium sulfate undoubtedly eliminates more residual pathogens while significantly shortens the conventional duration of systemic antibiotics administration. Moreover, similar to PMMA, the well-reported osteo-conductivity of calcium sulfate provides a crystalline structure for the osteoblasts perivascular mesenchymal tissues and osteoprogenitor, along which osteoblasts and the others crawl easily and eventually achieve the self-repair without autogenous bone grafts[19, 20]. While combined with the biodegradation characteristic of calcium sulfate, it allows orthopedists to accomplish debridement and reconstruction within one operation only, significantly avoiding the redundant reconstructive procedures.

With application of antibiotic-loaded calcium sulfate implantation, generally satisfying outcomes were achieved in our study at the end of follow-up. This was well illustrated by the fact that $88.4 \%$ of our patients achieved infection remission after first operation. Even for patients with recurrence, a chance for re-debridement could be preserved and managed accordingly. This extremely high remission rates were similar to previous study of J. Y. Ferguson et al, who managed 144 cases with type III chronic osteomyelitis (195 cases, totally) using local debridement and implantation of tobramycin-contained calcium sulfate beads. Their records showed only 11 cases (7.6\%) of type III chronic osteomyelitis recurred within a mean follow-up of 3.7 years, while most of cases were successfully managed by re-debridement and antibiotics usuage[21]. In another comparative study, Albert Ferrando et al compared the efficacy of bioglass (BAG-S53P4) and calcium sulphate antibiotic beads in the treatment of chronic osteomyelitis. For 13 patients (7 on tibia) with antibiotic-loaded calcium sulfate implantation, 12 patients achieved infection remission during the follow-up[22]. However, although the samples of their study were relatively large, it contained a variety of infection sites (femur, tibia, humerus, radius, ulnar, pelvic and even calcaneus) and four types of Cierny-Mader classification. Thus, their study ineluctably lacked of the in-depth discussion on a single type and site of chronic osteomyelitis.

While infection elimination was effective, associated complications were also of concern. Prolonged aseptic drainage was the most frequent recorded complication in our study, with a relatively high rate of $30.0 \%$. This incidence was various from person to person, primarily depending on the volume of implanted calcium sulfate and the abundance of soft tissues coverage. To our study, poor soft tissues coverage in the medial surface of tibia, scar formation surrounding to the focus and large volume implantation of calcium sulfate might interpret the high incidence of postoperative drainage. Kallala $R$ et al previously concluded a $4.2 \%$ incidence of prolonged aseptic drainage after calcium sulfate implantation[9], compared to higher incidence of $15.4 \%[21], 33 \%[23], 27 \%[24]$ respectively in other studies. If not accompanied with typical presentations, positive inflammatory markers and imaging examination, prolonged aseptic drainage alone should not be considered as a sign of infection recurrence, since it is a common presentation produced by the gradual degradation of calcium sulfate. Though the liquid is sterile, however, immediate management of this postoperative drainage is of great necessity, or a soggy gauze is prone to cause wound infection. Generally, it can be well-managed with regular dressing and wound care. Other effective methods might include employing a flap or muscle flap when soft tissue of tibia is too poor to cover, using lateral incision instead of medial incision, and implanting less calcium sulfate if a medial incision is applied. Another complication needing attention is the, not very satisfying, self-restored shape of tibia on 17 cases during the follow-up, which was 
illustrated on X-rays. We suspect this situation might be attributed to the unconfirmed relation between degradation of calcium sulfate and growth of osteoblasts, yet there is no evidence in former studies was detected to support our hypothesis. Although the shape of the tibia in these cases was not well-restored, however, there was no operative-related fracture or tibial bowing effect was recorded during the follow-up, which means that the tibia still has enough strength to bear the weight.

To our best knowledge, separate study for evaluating C-M type III tibial osteomyelitis is still rare. Our study might be the first to assess the outcomes of this technique for single-stage treatment of chronic localized tibial osteomyelitis, with a larger number of patients. The drawbacks of our study were also obvious. To begin with, its retrospective characteristic means only limited information was available, thus, inevitably reduces the credibility of our study. In addition, outcomes of this study were not compared with those of other surgical methods, a comparative study is necessary to be carried out.

\section{Conclusion}

Local debridement combined with antibiotic-loaded calcium sulfate as a single-stage treatment is effective on treating chronic localized tibial osteomyelitis.

\section{Abbreviations}

C-M: Cierny-Mader; PMMA: Polymethylmethacrylate; MIC: Minimum Inhibitory Concentration; VAC: Vacuum Assisted Closure; ESR: Erythrocyte Sedimentation Rate; CRP: C-reactive protein; WBC: White Blood Cell; MRI: Magnetic Resonance Imaging.

\section{Declarations}

\section{Acknowledgements}

The authors thank all patients and staffs who made this study possible.

\section{Funding}

This study was not externally founded

\section{Availability of data and materials}

The datasets used and analyzed during the current study are available from the corresponding author on reasonable request.

\section{Authors' contributions}

$\mathrm{CHZ}$, YR, AA contributed equally to this work. Scientific idea: $\mathrm{CHQ}, \mathrm{CHZ}$; Project planning: $\mathrm{CHQ}, \mathrm{CHZ}, \mathrm{YR}$, JF; Manuscript writing: $\mathrm{CHQ}, \mathrm{CHZ}, \mathrm{AA}$; Manuscript revision: $\mathrm{CHZ}$, AA, YR; All authors read and approved the final manuscript.

\section{Ethics approval and consent to participate}

Medical Ethical Committee of Nanfang Hospital of Southern Medical University has approved the Research ethics approval. All included patients consented to participate in this study and a signed consent form was obtained from each subject before testing. All procedures were conducted according to the Declaration of Helsinki.

\section{Consent for publication}

Not applicable.

\section{Competing interests}

The authors declare that they have no competing interests. 


\section{References}

1. Jiang N, Ma Y, Jiang Y, Zhao X, Xie G, Hu Y, Qin C, Yu B: Clinical Characteristics and Treatment of Extremity Chronic Osteomyelitis in Southern China. MEDICINE 2015, 94(42):e1874.

2. Bhattacharya R, Kundu B, Nandi SK, Basu D: Systematic approach to treat chronic osteomyelitis through localized drug delivery system: Bench to bed side. Materials Science and Engineering: C 2013, 33(7):3986-3993.

3. Cierny GR, Mader JT, Penninck JJ: A clinical staging system for adult osteomyelitis. Clin Orthop Relat Res 2003(414):724.

4. Parsons B, Strauss E: Surgical management of chronic osteomyelitis. The American Journal of Surgery 2004, 188(1):5766.

5. Wahl P, Guidi M, Benninger E, Ronn K, Gautier E, Buclin T, Magnin JL, Livio F: The levels of vancomycin in the blood and the wound after the local treatment of bone and soft-tissue infection with antibiotic-loaded calcium sulphate as carrier material. BONE JOINT J 2017, 99-B(11):1537-1544.

6. Kinik H, Karaduman M: Cierny-Mader Type III chronic osteomyelitis: the results of patients treated with debridement, irrigation, vancomycin beads and systemic antibiotics. INT ORTHOP 2008, 32(4):551-558.

7. Zumiotti AV, Teng HW, Ferreira MC: Treatment of post-traumatic tibial osteomyelitis using microsurgical flaps. $J$ RECONSTR MICROSURG 2003, 19(3):163.

8. Buchholz HW, Engelbrecht H: [Depot effects of various antibiotics mixed with Palacos resins]. CHIRURG 1970, 41(11):511-515.

9. Kallala R, Harris WE, Ibrahim M, Dipane M, McPherson E: Use of Stimulan absorbable calcium sulphate beads in revision lower limb arthroplasty: Safety profile and complication rates. BONE JOINT RES 2018, 7(10):570-579.

10. Qin $\mathrm{CH}$, Zhang HA, Chee YH, Pitarini A, Adem AA: Comparison of the use of antibiotic-loaded calcium sulphate and wound irrigation-suction in the treatment of lower limb chronic osteomyelitis. INJURY 2019, 50(2):508-514.

11. Beuerlein MJ, McKee MD: Calcium sulfates: what is the evidence? J ORTHOP TRAUMA 2010, 24 Suppl 1:S46-S51.

12. De Long WJ, Einhorn TA, Koval K, McKee M, Smith W, Sanders R, Watson T: Bone grafts and bone graft substitutes in orthopaedic trauma surgery. A critical analysis. J BONE JOINT SURG AM 2007, 89(3):649-658.

13. Yikemu X, Tuxun A, Nuermaimaiti M, Abudukeyimu A, Shayiti A: Effects of Vacuum Sealing Drainage Combined with Ilizarov Bone Transport Technique in the Treatment of Tibial Traumatic Osteomyelitis. MED SCI MONITOR 2019, 25:6864-6871.

14. Simpson AH, Deakin M, Latham JM: Chronic osteomyelitis. The effect of the extent of surgical resection on infectionfree survival. J Bone Joint Surg Br 2001, 83(3):403-407.

15. Donlan RM: Biofilms: microbial life on surfaces. EMERG INFECT DIS 2002, 8(9):881-890.

16. Beals RK, Bryant RE: The Treatment of Chronic Open Osteomyelitis of the Tibia in Adults. CLIN ORTHOP RELAT R 2005, \&NA;(433):212-217.

17. Miclau T, Dahners LE, Lindsey RW: In vitro pharmacokinetics of antibiotic release from locally implantable materials. $J$ ORTHOP RES 1993, 11(5):627-632.

18. Cooper JJ, Florance H, McKinnon JL, Laycock PA, Aiken SS: Elution profiles of tobramycin and vancomycin from highpurity calcium sulphate beads incubated in a range of simulated body fluids. J BIOMATER APPL 2016, 31(3):357-365.

19. Beuerlein MJ, McKee MD: Calcium sulfates: what is the evidence? J ORTHOP TRAUMA 2010, 24 Suppl 1:S46-S51.

20. Turner TM, Urban RM, Hall DJ, Chye PC, Segreti J, Gitelis S: Local and systemic levels of tobramycin delivered from calcium sulfate bone graft substitute pellets. Clin Orthop Relat Res 2005(437):97-104.

21. Ferguson JY, Dudareva M, Riley ND, Stubbs D, Atkins BL, McNally MA: The use of a biodegradable antibiotic-loaded calcium sulphate carrier containing tobramycin for the treatment of chronic osteomyelitis: a series of 195 cases. BONE JOINT J 2014, 96-B(6):829-836. 
22. Ferrando A, Part J, Baeza J: Treatment of Cavitary Bone Defects in Chronic Osteomyelitis: Bioactive glass S53P4 vs. Calcium Sulphate Antibiotic Beads. Journal of Bone and Joint Infection 2017, 2(4):194-201.

23. Badie AA, Arafa MS: One-stage surgery for adult chronic osteomyelitis: concomitant use of antibiotic-loaded calcium sulphate and bone marrow aspirate. INT ORTHOP 2019, 43(5):1061-1070.

24. Romano CL, Logoluso N, Meani E, Romano D, De Vecchi E, Vassena C, Drago L: A comparative study of the use of bioactive glass S53P4 and antibiotic-loaded calcium-based bone substitutes in the treatment of chronic osteomyelitis: a retrospective comparative study. BONE JOINT J 2014, 96-B(6):845-850.

\section{Table}

Table 1. Preoperative characteristics and follow-up outcomes of 42 patients (43 limbs). 


\begin{tabular}{|c|c|c|c|c|c|c|c|c|c|c|c|c|c|}
\hline No. & $\begin{array}{l}\text { Age } \\
\text { /Sex }\end{array}$ & Side & Infected by & $\begin{array}{c}\text { Cigarette/Alcohol } \\
\text { abuse }\end{array}$ & $\begin{array}{l}\text { Systemic } \\
\text { disease }\end{array}$ & $\begin{array}{c}\text { Positive } \\
\text { inflammatory } \\
\text { markers }\end{array}$ & $\begin{array}{c}\text { C - M } \\
\text { classification }\end{array}$ & Organisms & Flap & $\begin{array}{l}\text { External } \\
\text { fixation }\end{array}$ & $\begin{array}{c}\text { Hospital } \\
\text { stay } \\
\text { (days) }\end{array}$ & $\begin{array}{c}\text { Follow- } \\
\text { up } \\
\text { (months) }\end{array}$ & Outcomes \\
\hline 1 & $46 / \mathrm{F}$ & $\mathrm{L}$ & Trauma & - & - & ESR & III A & - & - & - & 6 & 35.9 & $\begin{array}{l}\text { Remission, } \\
\text { Slight pain }\end{array}$ \\
\hline 2 & $44 / \mathrm{M}$ & $\mathrm{L}$ & Trauma & - & - & - & III A & S. aureus & - & - & 9 & 34.3 & Remission \\
\hline 3 & $24 / \mathrm{M}$ & $\mathrm{R}$ & Trauma & - & - & - & IIIA & - & - & - & 7 & 32.7 & Remission \\
\hline 4 & $63 / \mathrm{M}$ & $\mathrm{R}$ & Trauma & - & - & - & III A & - & - & - & 8 & 33.1 & Remission \\
\hline 5 & $40 / \mathrm{F}$ & $\mathrm{L}$ & Trauma & - & - & ESR & IIIA & - & - & - & 9 & 32.9 & $\begin{array}{c}\text { Remission, } \\
\text { Joint stiffness }\end{array}$ \\
\hline 6 & $32 / \mathrm{F}$ & $\mathrm{L}$ & Trauma & - & - & - & IIIA & - & - & - & 10 & 30.9 & Remission \\
\hline 7 & $45 / \mathrm{M}$ & $\mathrm{L}$ & Trauma & - & - & - & IIIA & S. aureus & - & Yes & 13 & 26.4 & Remission \\
\hline 8 & $58 / \mathrm{M}$ & $\mathrm{L}$ & Haematogenous & Cigarette & - & WBC, ESR & III $\mathrm{B}^{\mathrm{S}}$ & S. aureus & - & - & 13 & 24.9 & Remission \\
\hline 9 & $25 / F$ & $\mathrm{~L}$ & Haematogenous & - & - & ESR & III A & - & - & - & 15 & 36.4 & $\begin{array}{c}\text { Remission, } \\
\text { Fibrous scar } \\
\text { formation }\end{array}$ \\
\hline 10 & $40 / \mathrm{F}$ & $\mathrm{R}$ & Haematogenous & - & - & ESR & III A & - & - & & 11 & 32.7 & Remission \\
\hline 11 & $43 / \mathrm{M}$ & $\mathrm{R}$ & Trauma & - & - & - & IIIA & - & - & - & 10 & 40.9 & $\begin{array}{c}\text { Redebridment } \\
\text { and Bone } \\
\text { transport }\end{array}$ \\
\hline 12 & $31 / \mathrm{F}$ & $\mathrm{R}$ & Haematogenous & - & - & - & III A & - & - & - & 17 & 24.1 & $\begin{array}{c}\text { Remission, } \\
\text { skin traction } \\
\text { to cover } \\
\text { wound }\end{array}$ \\
\hline 13 & $60 / \mathrm{F}$ & $\mathrm{L}$ & Trauma & - & - & - & III A & - & - & - & 15 & 38.2 & Remission \\
\hline 14 & $61 / \mathrm{M}$ & $\mathrm{L}$ & Trauma & - & - & ESR & III A & $\begin{array}{c}P . \\
\text { Aeruginosa, } \\
\text { E. faecalis }\end{array}$ & Yes & Yes & 37 & 89.9 & $\begin{array}{c}\text { Redebridment } \\
\text { and Bone } \\
\text { transport }\end{array}$ \\
\hline 15 & $16 / \mathrm{F}$ & $\mathrm{R}$ & Trauma & - & - & - & III A & S. aureus & - & - & 10 & 70.8 & Remission \\
\hline 16 & $74 / \mathrm{F}$ & $\mathrm{L}$ & Trauma & - & - & ESR & III $B^{S}$ & S. aureus & - & Yes & 20 & 75.8 & Remission \\
\hline 17 & $24 / F$ & $\mathrm{R}$ & Trauma & - & - & ESR & III B ${ }^{S}$ & - & - & Yes & 32 & 73.2 & $\begin{array}{c}\text { Redebridment } \\
\text { and Bone } \\
\text { transport }\end{array}$ \\
\hline 18 & $53 / \mathrm{M}$ & $\mathrm{L}$ & Trauma & - & - & ESR & III A & $\begin{array}{c}A . \\
\text { baumannii }\end{array}$ & - & Yes & 46 & 77.5 & Remission \\
\hline 19 & $26 / \mathrm{M}$ & $\mathrm{R}$ & Trauma & - & - & - & III A & S. aureus & - & - & 8 & 67.2 & Remission \\
\hline 20 & $57 / F$ & $\mathrm{R}$ & Trauma & - & Hypertension & - & III A & $\begin{array}{c}\text { K. } \\
\text { pneunoniae }\end{array}$ & - & - & 12 & 49.9 & Remission \\
\hline 21 & $46 / \mathrm{M}$ & $\mathrm{R}$ & Haematogenous & - & - & ESR & III A & - & - & - & 11 & 48.5 & Remission \\
\hline 22 & $59 / \mathrm{F}$ & $\mathrm{L}$ & Penetration & - & Hypertension & ESR & $\operatorname{IIIB}^{\mathrm{L}}$ & E. cloacae & - & - & 8 & 19.6 & $\begin{array}{c}\text { Redebridment } \\
\text { and flap } \\
\text { coverage }\end{array}$ \\
\hline 23 & $23 / \mathrm{M}$ & $\mathrm{R}$ & Trauma & - & - & - & III A & S. aureus & - & - & 7 & 68.5 & Remission \\
\hline 24 & $25 / M$ & $\mathrm{~L}$ & Haematogenous & - & - & - & III A & E. faecalis & - & - & 13 & 59.6 & Remission \\
\hline 25 & $46 / \mathrm{M}$ & $\mathrm{L}$ & Trauma & - & Diabetes & ESR & III $B^{S}$ & $\begin{array}{c}P . \\
\text { aeruginosa }\end{array}$ & - & Yes & 29 & 52.7 & Remission \\
\hline 26 & $44 / \mathrm{M}$ & $\mathrm{L}$ & Trauma & - & - & - & III A & - & - & Yes & 33 & 47.6 & $\begin{array}{c}\text { Redebridment } \\
\text { and bone } \\
\text { transport }\end{array}$ \\
\hline 27 & $42 \mathrm{M}$ & $\mathrm{L}$ & Trauma & - & - & - & III A & S. aureus & - & - & 9 & 37.3 & Remission \\
\hline 28 & $30 / \mathrm{M}$ & $\mathrm{R}$ & Trauma & Cigarette & - & - & III $\mathrm{B}^{\mathrm{S}}$ & - & - & Yes & 12 & 46.4 & Remission \\
\hline 29 & $54 / \mathrm{M}$ & $\mathrm{R}$ & Trauma & - & - & - & III A & $\begin{array}{c}\text { S. } \\
\text { haemolyticus }\end{array}$ & - & Yes & 17 & 43.4 & Remission \\
\hline 30 & $39 / \mathrm{F}$ & $\mathrm{R}$ & Haematogenous & - & - & - & III A & - & - & - & 7 & 39.3 & Remission \\
\hline 31 & $40 / \mathrm{F}$ & $\mathrm{L}$ & Haematogenous & - & - & - & III A & - & - & - & 11 & 28 & Remission \\
\hline 32 & $26 / M$ & $\mathrm{~L}$ & Haematogenous & - & - & ESR & III A & - & - & Yes & 16 & 42.1 & Remission \\
\hline 33 & $63 / F$ & $\mathrm{~L}$ & Haematogenous & - & - & ESR & III A & S. aureus & - & - & 23 & 70.7 & $\begin{array}{l}\text { Remission, } \\
\text { Slight pain }\end{array}$ \\
\hline 34 & $39 / \mathrm{F}$ & $\mathrm{L}$ & Penetration & - & - & ESR & III A & - & - & - & 8 & 53.6 & $\begin{array}{l}\text { Remission, } \\
\text { Slight pain }\end{array}$ \\
\hline 35 & $64 / \mathrm{M}$ & $\mathrm{R}$ & Penetration & - & - & ESR & IIIB $^{S}$ & E. coli & Yes & - & 14 & 72.5 & $\begin{array}{c}\text { Remission, } \\
\text { Powerlessness }\end{array}$ \\
\hline 36 & $30 / \mathrm{M}$ & $\mathrm{R}$ & Trauma & - & - & - & III A & S. aureus & - & - & 11 & 44.8 & $\begin{array}{l}\text { Remission, } \\
\text { Discomfort }\end{array}$ \\
\hline 37 & $48 / \mathrm{M}$ & $\mathrm{R}$ & Trauma & - & - & ESR & III A & S. aureus & - & - & 24 & 50.9 & Remission \\
\hline 38 & $41 / \mathrm{F}$ & $\mathrm{R}$ & Trauma & - & - & ESR & III A & - & - & Yes & 32 & 12.8 & $\begin{array}{c}\text { Remission, } \\
\text { Claudication, } \\
\text { Discomfort }\end{array}$ \\
\hline 39 & $64 / \mathrm{M}$ & $\mathrm{L}$ & Trauma & - & - & ESR & III A & $\begin{array}{c}\text { A. } \\
\text { hydrophila }\end{array}$ & - & Yes & 22 & 12.9 & Remission \\
\hline
\end{tabular}




\begin{tabular}{|c|c|c|c|c|c|c|c|c|c|c|c|c|c|}
\hline 40 & $61 / \mathrm{M}$ & $\mathrm{L}$ & Trauma & - & - & ESR & III A & - & - & - & 18 & 14.2 & Remission \\
\hline 41 & $43 / F$ & $\mathrm{~L}$ & Haematogenous & - & - & - & III A & - & - & - & 16 & 15.6 & $\begin{array}{l}\text { Remission, } \\
\text { Slight pain }\end{array}$ \\
\hline 42 & $27 / F$ & $\mathrm{R}$ & Trauma & - & - & ESR & III A & $\begin{array}{c}P . \\
\text { aeruginosa }\end{array}$ & - & - & 22 & 16.3 & $\begin{array}{c}\text { Remission, } \\
\text { Slight } \\
\text { Discomfort }\end{array}$ \\
\hline 43 & $64 / \mathrm{F}$ & $\mathrm{L}$ & Trauma & - & - & ESR & III A & - & - & Yes & 22 & 17.5 & Remission \\
\hline
\end{tabular}

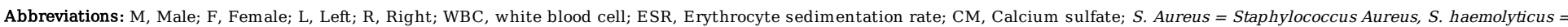

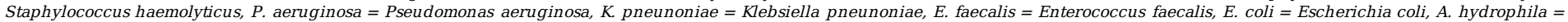
Aeromonas hydrophila, E. cloacae = Enterobacter cloacae, $S$. marcescens = Serratia marcescens

\section{Figures}

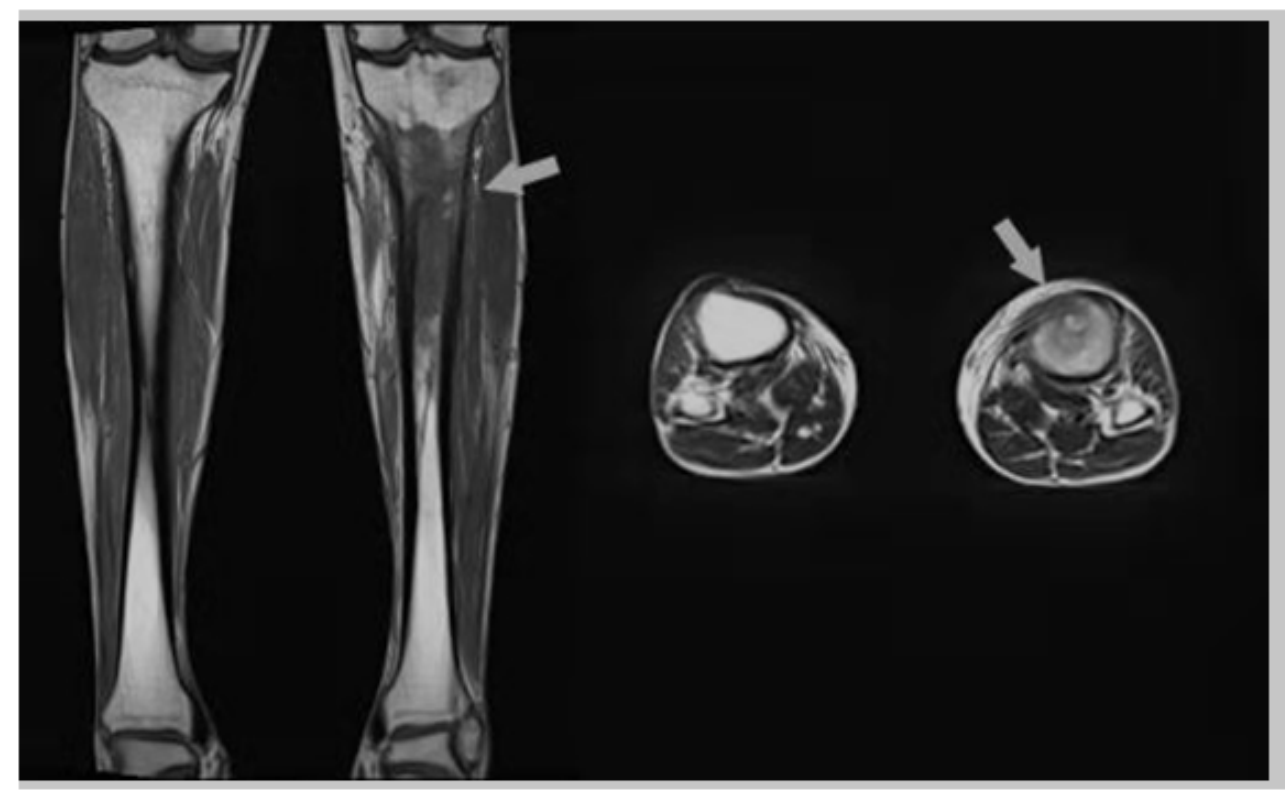

\section{Figure 1}

Preoperative MRI examination significantly assisted to define the diagnosis of C-M type III osteomyelitis and determine the extent of debridement.
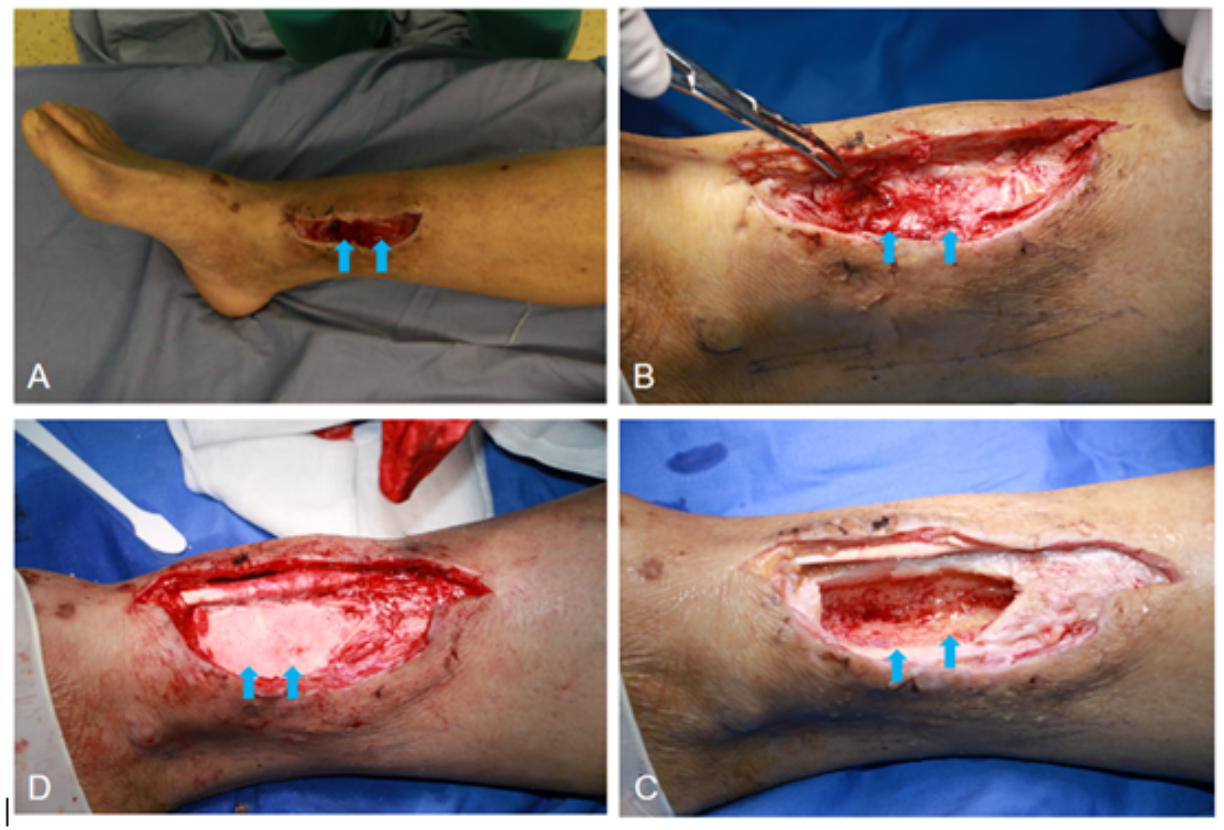


\section{Figure 2}

Intra-operative views of local debridement and antibiotic-loaded calcium sulfate implantation.

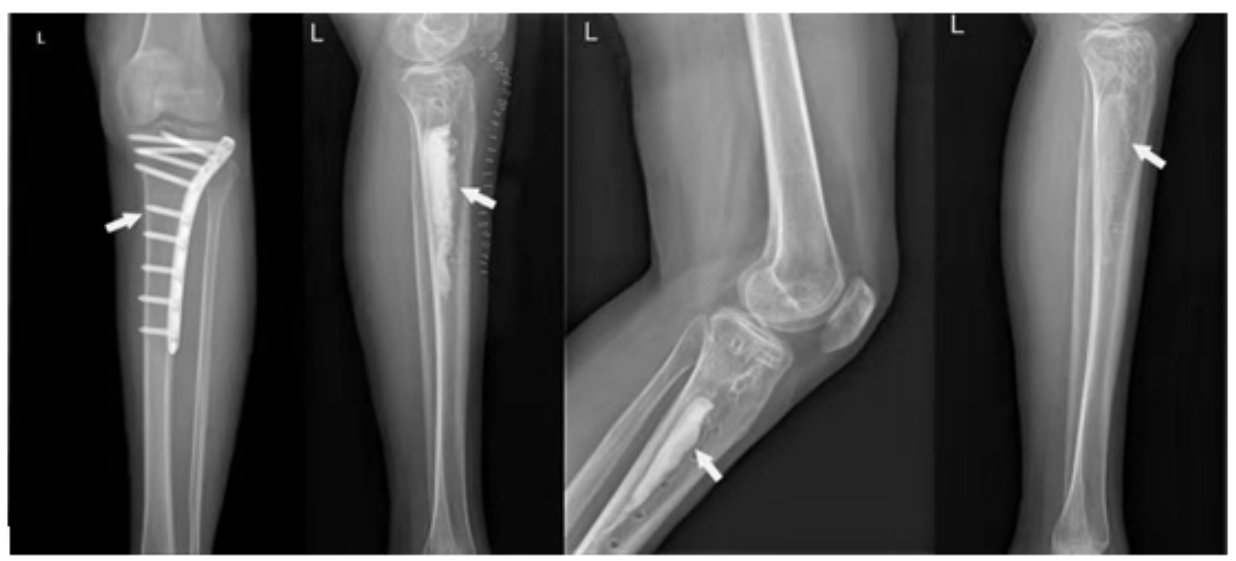

\section{Figure 3}

A patient with C-M type III tibial osteomyelitis received internal fixation removal and infected bone debridement, followed by implantation of antibiotic-loaded calcium sulfate. X-ray examination during the follow up showed dead space was generally substituted by new bone tissues.
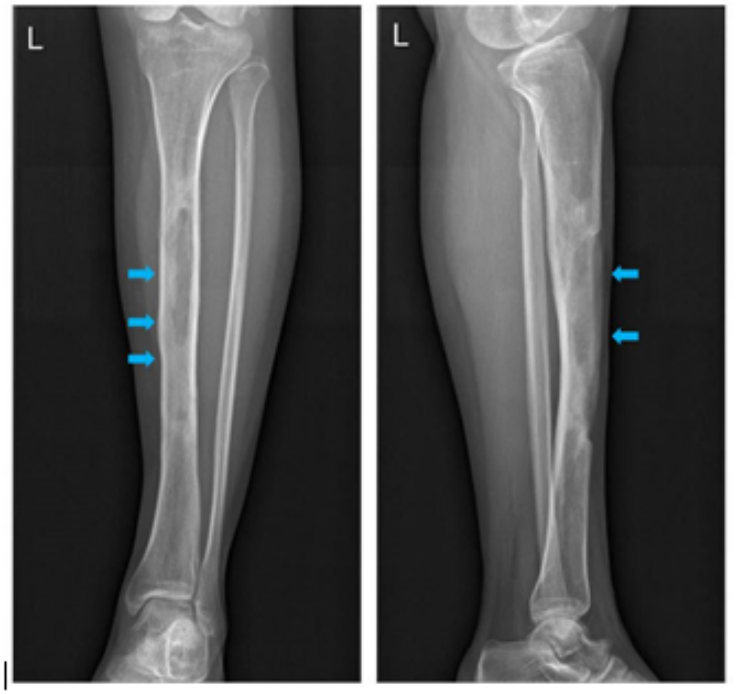

\section{Figure 4}

A patient received local debridement and calcium sulfate implantation. The X-ray after 6 months showed that the shape of tibia shaft was not well restored to the initial, but no fracture was detected. 